PLURAL, Revista do Programa de Pós-Graduação em Sociologia da USP, São Paulo, v. 16, n. 1, pp. 123-144, 2009

\title{
Internacionalização do Saber Jurídico e Redes Profissionais Locais: Um Estudo sobre Justiça Restaurativa em São Carlos - SP e São Caetano do Sul - SP
}

Juliana Tonche*

Resumo: Neste artigo, analiso o processo de articulação entre internacionalização do saber jurídico, aqui representada pela pauta da Justiça Restaurativa, e redes profissionais locais, em dois municípios paulistas: São Carlos e São Caetano do Sul. Na primeira cidade foi verificada uma perda de interesse pela Justiça Restaurativa, concomitante a uma configuraçáo local de disputas políticas em torno do campo dos adolescentes em conflito com a lei. Já a segunda cidade se constitui como uma das três regióes do país em que se estabeleceu um programapiloto de mediação nos moldes do tipo informal de resolução de conflitos em questão. A partir de uma revisão bibliográfica com base na área da Sociologia das Profissóes, discute-se como essa proposta de conteúdo mais político vem sendo tratada, mais especificamente no âmbito das profissốes do Direito, tendo como premissa que essas profissões, singulares em sua tradição histórica e forte ligação com o Estado, assumiram a neutralidade do saber e forte demarcação com o campo político como estratégia dominante para a construção de sua autonomia.

Palavras-chave: sociologia das profissóes; redes profissionais; Justiça Restaurativa; São Carlos; São Caetano do Sul.

Juridical Knowledge Internationalization and Local Professional Networks: a Study about Restorative Justice in São Carlos - SP and Sáo Caetano do Sul - SP (Brazil)

Abstract: In this article I analyze the process of articulation between the juridical knowledge internationalization, represented here by Restorative Justice, and local professional networks in two cities from the state of São Paulo: São Carlos and São Caetano do Sul. In the first city it was checked a loss of interest in restorative justice with a local configuration of disputes towards the minor with problems with the law. Then, the second city is constituted as one of the three

* Mestranda do Programa de Pós-Graduação em Sociologia da Universidade Federal de São Carlos. 
areas in this country in which it was established a pilot program of mediation in the shapes of the kind of informal resolution of conflicts indicated here. With a bibliography based on sociology of professions, it is discussed how this proposal, with a more political content, has been treated more specifically in the field of law professions, assuming that these professions, unique in their historical tradition and strong connection with State, have taken the neutrality of knowledge and strong delimitation with political field as the best strategy for the construction of their autonomy.

Keywords: sociology of professions; professional networks; Restorative Justice; São Carlos; São Caetano do Sul.

\section{INTRODUÇÃO'}

A Constituição Federal de 1988 representa um marco essencial para o Judiciário e o Ministério Público brasileiros, bem como para a discussão acerca do estado de direito. Isso porque, com a inclusão dos novos direitos sociais e coletivos e a criaçáo de mecanismos jurídicos para protegê-los, essas instituiçôes do Direito passaram a ter que lidar com conflitos de conteúdos social e político de uma forma não vista anteriormente.

Em dias atuais, além dos conflitos intersubjetivos de interesses, entram em pauta também questóes relacionadas ao meio ambiente, à proteção dos direitos do consumidor, interesses difusos e coletivos (Sadek, 2004; CavalCanti, I999).

A despeito de essas novas atribuiçôes não serem de fato tão recentes, elas apresentam resultados significativos até hoje e são merecedoras de maior atenção por parte dos pesquisadores. Isso porque, entre outros aspectos, a combinaçáo de dois tipos de atendimentos prestados por um órgáo do sistema de Justiça - aqueles referentes a questóes individuais e aqueles referentes a questóes coletivas - ainda causa estranhamento, pois, segundo alguns, parece confundir o que seria, tradicionalmente, duas funçốes distintas: a função jurídica e a função política (Ibidem).

Acresce-se ao quadro delineado dois fatos importantes: a nova centralidade do Judiciário diante dos demais poderes e sua maior exposição pública, decorrente, em parte, das novas demandas da população civil. Isso gerou grandes expectativas em relação à instituição, ao mesmo tempo em que tornou mais visíveis suas deficiências e fragilidades. Resultantes disso são as inúmeras discussóes que surgiram a respeito da judicialização da política e politização da Justiça, sobre a reforma do Judiciário, a existência ou não de uma crise do Judiciário, se essa crise é ou não estrutural, o que fazer para desafogar o sistema que está sobrecarregado e a insatisfaçáo de grande parte da população no que se refere ao seu acesso e ao funcionamento.

Com a adoção de novas funçôes, entre as mais eminentes, as de ordem política, os novos papéis das instituiçóes jurídicas reverberam diretamente sobre a dinâmica das profissōes do Direito. Nesse caso, conteúdos políticos passam a ser motivo de divergências internas entre esses profissionais, quando são entendidos como problemas de intervençấo em sua autonomia profissional, e novas incumbências modificam o perfil de alguns segmentos específicos.

I Apresento neste artigo os resultados parciais de uma pesquisa de mestrado de mesmo título. 2 Para saber mais sobre o assunto, consultar Sadek (op. cit.) e Vianna et al. (I999). 
É nesse contexto global de estímulo à redemocratização de países e, mais especificamente, de mudanças significativas nas profissóes do Direito brasileiro que o presente artigo procura analisar as relaçóes profissionais que se estabelecem em uma situação de vinda de uma pauta global para uma localidade. Essa pauta pode ser problemática, quando é entendida pelos profissionais como uma questáo de ingerência oriunda do campo político sobre a autonomia do profissionalismo ${ }^{3}$. Isso porque o ideário que se estabeleceu nesse meio é de neutralidade do conhecimento específico e forte demarcação com o campo político (Bonelli, 2002a; 2002b; 2007).

Nesse caso, a Justiça Restaurativa, tida como um dos modelos de resoluçáo de conflitos alternativos com maior visibilidade hoje e também por fazer parte do diálogo de expertise $e^{4}$ entre os profissionais dessa área, foi a via escolhida para tecer um estudo sociológico que contemplasse essas relaçôes profissionais.

A ideia é verificar como os profissionais se articulam em torno de uma pauta que está relacionada a uma vertente do Direito ligada às causas sociais, em que se amplia o espaço político na profissão, em contrapartida ao ideário de neutralidade difundido. Para tanto, escolheram-se como duas localidades de referência no estudo as cidades de São Carlos e São Caetano do Sul.

No primeiro município, a pauta da Justiça Restaurativa acabou se esvaindo e culminou com sua náo implantaçáo. $\mathrm{O}$ acompanhamento desse processo foi realizado com uma pesquisa de iniciação científica, realizada entre março de 2006 e agosto de 2007, que culminou na redação de uma monografia de conclusão de curso para a obtençáa do título de bacharel em Ciências Sociais. Já na segunda cidade, São Caetano do Sul, instituiu-se um programa-piloto sobre o tipo de Justiça informal em questáo, apoiado pelo Programa das Naçóes Unidas para o Desenvolvimento, PNUD, e pela Secretaria de Reforma do Judiciário. As outras duas regiôes em que também foram implantados os programas-piloto são o Núcleo Bandeirante (DF) e Porto Alegre (RS).

O objetivo é identificar que condiçóes favoreceram o desenvolvimento da proposta da Justiça Restaurativa em um lugar em detrimento do outro, considerando as implicaçóes que as "distâncias" das redes profissionais em relação aos centros de troca de expertise profissional podem assumir no contexto.

${ }_{3} \mathrm{O}$ profissionalismo pode ser caracterizado, sinteticamente, como uma forma específica de se exercer uma ocupação, em que são valorizados o conhecimento abstrato, a formação em cursos superiores, a autonomia profissional, entre outras características (FreIDSON, 200I), como poderá ser visto posteriormente no artigo.

4 Para Freidson (1998), a expertise profissional se constitui como uma síntese da ideologia profissional relacionada ao modo de organização do trabalho. É tida como conhecimento especializado de caráter abstrato, produzido nas universidades e obtido por meio de ensino superior. Para saber mais sobre o assunto, consultar também a produção de Dezalay e Garth (2002).

$5 \mathrm{O}$ estudo de caso de São Carlos tem como título "Importação e exportação de expertise jurídica ou ingerência política? O enquadramento local dos saberes globais no mundo do Direito: o caso da Justiça Restaurativa em São Carlos - SP" e foi realizado sob orientaçáo da Profa. Dra. Maria da Gloria Bonelli. Essa pesquisa resultou na composição de uma monografia de conclusão de curso, intitulada "Internacionalizaçáo do saber jurídico e poder local: o caso da Justiça Restaurativa em São Carlos - SP”, sob mesma orientação. 
A análise dessas relaçóes profissionais acompanha graus de proximidade e distância em relação à rede que se liga à internacionalizaçấo do saber especializado, de maneira que aqueles que não detêm acesso direto e se encontram mais distantes podem fazer uso dessa distância para não se envolverem com o conteúdo. Além disso, infere-se que os profissionais, especialmente aqueles do Direito, entendem o conteúdo da Justiça Restaurativa como um problema de ingerência em sua autonomia profissional, como, por exemplo, no caso de São Carlos, o que não foi verificado em Sáo Caetano do Sul, facilitando o desenvolvimento da proposta nesta segunda localidade.

Faz parte também do estudo, portanto, localizar os importadores desse saber, que podem se impulsionar na carreira da mesma forma que aqueles que estáo nos centros de troca de saber especializado, além dos diversos tipos de resistência com que a agenda global precisa lidar para ser colocada em prática.

Além disso, notou-se, com os trabalhos de campo nos dois municípios, que a institucionalizaçẫo da carreira nas profissōes em São Caetano do Sul é mais intensa que em São Carlos. Este último município, em contrapartida, apresenta uma rede profissional local mais ligada à política e já possui um programa de atendimento dos menores em situaçáo irregular, o Núcleo de Atendimento Integrado (NAI). Intenta-se mostrar, ao longo da análise, como essas duas características vão se impondo como barreiras no decorrer da pesquisa.

\section{JUSTIÇA RESTAURATIVA NO BRASIL}

A Justiça Restaurativa, além de se apresentar como outra opção ao tipo oficial, envolve características peculiares que a diferenciam desse modelo e das propostas de maior acesso à Justiça que o próprio Judiciário oferece dentro de suas jurisdiçóes. Um importante fator de diferenciação dos dois tipos são os objetivos que eles buscam: se a Justiça Comum se preocupa com a infraçáo da lei por parte do agressor e sua punição, a Justiça Restaurativa, de maneira diferente, foca na restauraçáo dos danos causados, dando atenção especial à vítima e às suas necessidades. $\mathrm{Na}$ verdade, com o modelo informal, intenta-se até mesmo escapar às denominaçôes usuais de vítima, réu, ofensor ou infrator (FouCAULT, 200I).

Para tentar restabelecer as relaçóes sociais que foram abaladas com o conflito, é realizado um procedimento consensual, normalmente denominado "círculo restaurativo", em que o infrator, mais um mediador - que pode ser um membro treinado da comunidade -, a vítima e, às vezes, mais pessoas da família e comunidade participam ativa e coletivamente na construção de soluçôes para o problema que foi instaurado (Gomes Pinto et al., 2005).

Em São Caetano do Sul, os mediadores dos círculos, que se autointitulam facilitadores de Justiça, explicam a todos os potenciais participantes do processo o que é a Justiça Restaurativa e como são os procedimentos. Se todos concordarem em participar, o círculo é realizado. Inicialmente, as partes componentes do conflito são ouvidas separadamente, depois, todos são reunidos em um círculo para tentarem entrar em acordo e verificar qual a melhor forma de resolverem a situação. 
A despeito de já existirem no país interessados na Justiça Restaurativa, bem como algumas publicaçôes e grupos de estudo do tema anteriores à inauguração dos três projetos-piloto ou sua idealização, comecemos a discorrer sobre a vinda da pauta a partir das falas dos próprios entrevistados. Esses relatos remontam o início do processo de vinda da Justiça Restaurativa - que culmina em sua implantaçáo efetiva - diante de certa efervescência surgida a partir do encontro entre principais agentes e do envolvimento que surgiu entre a entáo nova Secretaria de Reforma do Judiciário, que foi a responsável pelo financiamento e apoio institucional junto ao PNUD, e fomentadores do tema da Nova Zelândia, país pioneiro na utilização do modelo de mediação informal, ao contemplar em sua Carta Constitucional métodos de resolução de conflitos provenientes de grupos indígenas nacionais.

Esse envolvimento institucional, aqui no Brasil, teria surgido a partir de um convite feito à Secretaria da Reforma do Judiciário pelo Instituto Brasileiro do Direito Comparado (IDCB) - que recebia o entáo ministro da Justiça da Nova Zelândia, em um evento sobre Justiça Restaurativa, feito em parceria com a Associação dos Juízes do Distrito Federal. O juiz de Sáo Paulo, responsável pela expansão do projeto de Justiça Restaurativa para a regiáo de Heliópolis, afirma ter sido aquele quem pessoalmente informou o secretário Sérgio Renault ${ }^{6}$ sobre o que seria Justiça Restaurativa e, depois, sobre o evento que estaria acontecendo, com especialistas da Argentina, estudiosos brasileiros e juízes do Distrito Federal.

A Secretaria designou um assessor para ir ao evento, que afirmou só ter tomado conhecimento do que era a Justiça Restaurativa a partir desse convite, quando passou a pesquisar o tema para participar.

É importante ressaltar que a ida desses profissionais para atuarem na nova Secretaria aconteceu em um momento de mudanças políticas importantes, com a nomeação de Márcio Thomaz Bastos como ministro da Justiça pelo Presidente Luiz Inácio Lula da Silva (2003-2006; 2007-20I0). O novo ministro, que atuou durante todo o primeiro mandato do Presidente Lula e durante três meses do segundo mandato, ao levar consigo profissionais com posiçóes intelectuais ou políticas consoantes à sua, ajudou a impulsionar uma visão mais heterodoxa da profissão, o que vai ao encontro também da proposta do governo petista de maior acesso da populaçáo à Justiça.

A partir do evento em Brasília, foi surgindo um envolvimento progressivo da Secretaria com o tema, por meio do estreitamento de laços com pessoas já atuantes aqui no Brasil e com o programa da Nova Zelândia. Estudiosos de Nova Zelândia vieram dissertar sobre o tema, como Gabrielle Maxwell, da Universidade de Vitória, Nova Zelândia, bem como uma delegaçáo do Brasil, formada por um grupo de juízes, promotores e pelo próprio assessor, como representante do Executivo, foi até Nova Zelândia conhecer pessoalmente o funcionamento do programa. Nessa excursão, tiveram a oportunidade de visitar vários estados e ver como ocorre a operacionalização dos programas neozelandeses. Foi depois dessa visita ao país que surgiu o projeto da Secretaria: "Promovendo práticas restaurativas no Sistema de Justiça Brasileiro".

6 Sérgio Renault, advogado, foi o primeiro secretário da Reforma do Judiciário do Ministério da Justiça (2003-2005) e subchefe para assuntos jurídicos da Casa Civil da Presidência da República (2005-2006). 
Nesse ínterim, já havia uma parceria da Secretaria com o PNUD para fomentar programas alternativos de Justiça. Depois da viagem, o assessor sugeriu que fosse incluída nesse projeto, em comum, uma linha para tratar especificamente da questão da Justiça Restaurativa. A verba foi entấo aprovada, o que possibilitou o desenvolvimento dos projetos-piloto.

A seguir, foram transcritos dois excertos da entrevista realizada com o ex-assessor da Secretaria de Reforma do Judiciário, em que ficam bem ilustrados em que termos a Justiça Restaurativa veio se instalar no Brasil:

Pareceu prudente que nós firmássemos parcerias sólidas com juízes e promotores interessados na aplicação daquilo por dentro do Sistema de Justiça, para garantir efetividade prática, compromisso dos operadores, se não ser apenas, apenas não, mas não ser um programa puramente ligado à comunidade, até porque, no âmbito do Direito Criminal, onde tudo é institucionalizado, você tem poucos desvios do sistema formal no âmbito criminal. (...) É a partir daí que surge o programa "Promovendo práticas restaurativas no Sistema de Justiça Brasileiro", que eu propus, e o PNUD encampou. Nós desenvolvemos, conseguimos a linha de crédito e nós pensávamos em atuar na produção de conhecimento científico.

Então, essa chancela e esse apoio institucional do Ministério da Justiça acabam abrindo portas. Muitas vezes os tribunais falam: “O que é esse juiz aí? Esse ‘juizinho’ de primeira instância está pensando demais, querendo revolucionar demais”. E aí, quando você tem uma iniciativa do MJ, o Ministério da Justiça apoiando, esses juízes também, talvez, consigam romper obstáculos e barreiras naturais dentro daquelas estruturas conservadoras, arcaicas que são os Tribunais de Justiça.

O auxílio financeiro inicial foi pensado para três projetos-piloto, e foram escolhidos três projetos: o do Núcleo Bandeirante (Distrito Federal), atuando no Juizado Especial Criminal; em São Caetano do Sul, São Paulo, com foco na área da infância e juventude e em integração com o sistema público educacional; e Rio Grande do Sul (Porto Alegre), onde vem sendo aplicado, na Vara de Execuçōes de Medidas Socioeducativas, na área de Infância e Juventude.

É interessante salientar que, na verdade, São Caetano do Sul não foi a primeira opção pensada para integrar o projeto inicial. A ideia era que fossem instalados programas em Brasília, Porto Alegre e São Paulo, mas o juiz de Sáo Paulo, que hoje é responsável pela ampliação do projeto para Heliópolis, teria recusado o convite por várias razóes: falta de disponibilidade de tempo - ele estava há pouco tempo na assessoria do Tribunal em Sáo Paulo - e pesava para ele o fato de ser um programa novo, o que implica, além de tempo, muita responsabilidade.

\section{O PROFISSIONALISMO NAS CARREIRAS JURÍDICAS}

O presente estudo tem embasamento científico na área da Sociologia das Profissóes, que contribui para a análise, na medida em que fornece as ferramentas necessárias para entender 
como se processam as dinâmicas profissionais dos grupos. Mais especificamente, tratando-se das profissóes do Direito, distintas em sua tradição histórica e no envolvimento com o Estado e as leis, verifica-se como foi construída a ideia de necessidade da neutralidade do saber e intensa demarcaçáo com o campo político, bem como a contestação disso (BonelLI, 2002a; 2002b; 2007). Destaca-se, também, a produção de Freidson (1998; 200I), para a análise do profissionalismo, e dos autores Dezalay e Garth (op. cit.), que trabalham com a ideia de existência de homologias entre as posiçôes de exportadores e importadores em seus campos e de como isso poderia facilitar ou dificultar a incorporação de pautas que se ligam à rede internacional de saberes.

Freidson é um importante autor dentro da recente história da Sociologia das Profissóes. Ele faz parte do grupo de autores que promoveram o chamado movimento crítico, nas décadas de 70 e 8o, em relação à perspectiva funcionalista que dominava até então, quando ainda se buscavam as definiçóes do campo de estudo. Esse autor foi de grande importância para a pesquisa, dada a riqueza de sua produção em relação à tentativa de definição de um modelo teórico que abarca diversas variáveis; além disso, ele trabalha com a ideia de profissionalismo, que também é de grande valia para o estudo.

Freidson tenta dar um caráter de cientificidade à questáo da profissão, a partir da criaçáo de um modelo. Em suas próprias palavras, ele diz:

Desenvolvo um tipo ideal que denomino profissionalismo e, a partir dele, analiso os órgãos e recursos exigidos para que ele se estabeleça. Trato o tipo ideal como um conjunto constante de características e os órgãos e recursos como variáveis que interagem (FREIDSON, 1996, p. I42).

Em sua obra Profissionalism, the Third Logic (200I), ele expóe que as profissôes têm uma lógica interna que é diferente tanto da lógica que rege o mercado, em que supostamente reina a escolha racional do consumidor, quanto da lógica burocrática, que atua por intermédio do governo ou das empresas, com base no princípio gerencial da administraçáo racional.

Para ele, o monopólio é essencial ao profissionalismo, o que se opóe à lógica de concorrência do livre mercado. Ele nos diz que as profissóes exemplificam casos em que as ocupaçóes conseguem exercer um controle sobre o trabalho na mesma intensidade daquele exercido pelos consumidores e gerentes. Esse controle ocupacional está ligado à institucionalização do corpo de conhecimento de cada profissáo em disciplinas, no estabelecimento de credenciais acadêmicas como condição para a entrada no mundo do trabalho e do controle jurisdicional.

Nesse caso, o profissionalismo pode, entáo, ser caracterizado sinteticamente como uma forma específica de se exercer uma ocupação e de se estabelecer relaçôes no mundo do trabalho, construídas historicamente. Ele representa um tipo alternativo aos modelos burocrático e de mercado, em que é valorizado o conhecimento abstrato, a formação em cursos superiores, a autonomia profissional, a neutralidade da expertise, entre outras características (Ibidem). Além 
disso, é interessante frisar que, não obstante a ampla propagação do profissionalismo, os tipos competem entre si por sua preponderância ${ }^{7}$.

Da mesma forma, também é central fundamentar algumas das bases pelas quais ergo meu argumento; neste caso, trabalho com a ideia de uma aparente discordância de dois modelos de resolução de conflitos, e isso representa mais do que uma simples divergência, fundamenta a ideia de heterogeneidade nos grupos profissionais envolvidos.

Nesse sentido, temos que atentar para a formação histórica do Direito no Brasil, sua tradiçấo e as conexóes que se estabeleceram com os demais poderes.

Sob uma perspectiva histórica, temos que a influência predominante na área jurídica no Brasil é a da tradiçẫo europeia, uma linha que diverge do modelo que se instaurou nos Estados Unidos, que alia advocacia empresarial e de interesse público, voltado para o acesso à Justiça (nesse caso, a advocacia voluntária aumentava o status do currículo desses chamados advogados de Wall Street do século XIX) ${ }^{8}$.

De maneira diferente, a ideologia profissional que se consolidou aqui entre os profissionais do Direito é a que ressalta a neutralidade da expertise e acentua o apoliticismo, acarretando uma divisão bem marcada entre a profissão e a política. Halliday (1987) afirma, em seu estudo, que essa foi a melhor postura que as profissóes escolheram, isto é, afirmarem-se como antipolíticas, tentando, dessa forma, protegerem-se dos problemas advindos da política convencional. No caso específico desses grupos profissionais, o afastamento da política foi a via para a consolidação de sua autonomia.

É interessante destacar, entretanto, que, na prática, essa divisão não é tão facilmente demarcada' ${ }^{9}$ ainda mais se considerarmos o histórico de ligação existente entre a lei e a política.

A situação de tentativa de consolidação da neutralidade vem sendo confrontada, principalmente, por diversos grupos que apregoam uma prática da advocacia voltada para o compromisso social ${ }^{10} \mathrm{e}$ uma intervenção menos hierarquizada da relação profissional-cliente. Nesse caso, tanto pauta sobre o acesso à Justiça quanto iniciativas para o aumento dos canais de acesso da populaçáo à Justiça fazem parte das trocas de expertise entre os profissionais do Direito.

A implantação de novos tipos de Justiça informal é uma das formas que podem fortalecer o ideário heterodoxo que vem tomando espaço entre as tendências existentes nas profissóes do Direito. Se a visáo ortodoxa de neutralidade se depara com uma judicializaçáo da política, como pretendem alguns, o movimento voltado para as causas sociais, em que, de certa forma, amplia-se o espaço político na profissão, vem chamando a atenção.

7 Sobre o profissionalismo, Bonelli (2007) destaca ainda suas quatro principais conceituaçôes: o tecnocrático, o cívico, o democrático e o organizacional.

8 Ver Dezalay e Garth (2002).

9 Para uma análise das relaçóes que as profissóes do Direito estabeleceram com o Estado, bem como da consolidação do modo de organizaçáo do trabalho denominado profissionalismo, dentro de uma perspectiva histórica, consultar Bonelli (2002b).

Io Ver também Engelman (2006b). 
Esse novo segmento dentro do mundo do Direito gera defesas e críticas a programas desse cunho, como tento verificar ao longo da análise.

É importante ressaltar que essa perspectiva é amparada por Dezalay e Garth (2000; 2002), que argumentam sobre a existência de uma circulação internacional de ideias, ou seja, parte-se da premissa de que essas ideias estão em fluxo. Mais do que isso, no artigo "A dolarizaçáo do conhecimento técnico profissional e do Estado: processos transnacionais e questôes de legitimação na transformaçáo do Estado", os autores supracitados relatam que os Estados estáo crescentemente inseridos em um mercado internacional de conhecimento técnico, centrado no circuito universitário dos Estados Unidos.

Desse conceito, que se vincula a uma tradiçáo bourdieusiana de ideia de campo - aqui o campo passa a ser transnacional -, os autores refinaram para aquilo que denominamos "importação e exportaçáo de saber especializado" ou "importação e exportação de expertise". Dezalay e Garth passam a considerar a importância da posiçẫo dos agentes e daí a relevância de se verificar como a pauta global dos tipos de mediaçáo de conflitos informais vem sendo recebida pelas localidades, especialmente pelas profissôes do Direito. Nesse caso, começa-se a disseminar no Brasil e, em geral, no hemisfério sul a associaçáo entre Direito Econômico e Direitos Humanos, que é mais amplamente difundida entre os países do hemisfério norte, além das diferentes receptividades que passam a ser alvo de estudos.

\section{O CASO DA JUSTIÇA RESTAURATIVA EM SÃO CARLOS}

A cidade de São Carlos constituiu-se como meu primeiro objeto de pesquisa, porque foi verificada ali uma perda de interesse pela Justiça Restaurativa, desde sua tentativa de implantaçáo, em 2005, concomitante a uma configuraçáo local de disputas políticas em torno do campo dos adolescentes em conflito com a lei.

Foi possível verificar, desde o início, que a Justiça Restaurativa tinha que lidar, nesse campo, com a forte imagem do Núcleo de Atendimento Integrado (NAI). Esse programa, que atende os menores em situaçáo irregular no município, impulsiona a imagem do governo - assim como o reconhecimento público dos profissionais atuantes no programa - por intermédio de sua ampla e positiva visibilidade.

A cidade ganhou projeção na mídia, sendo citada como um exemplo no tratamento dos adolescentes em conflito com a lei. O programa desenvolvido na cidade tem mostrado resultados satisfatórios, que podem ser comprovados pelos números divulgados: se, em I998, foram registrados quinze homicídios praticados por adolescentes, entre 200I e 2005, o número caiu para dois por ano, e nenhum caso foi registrado em 2006; o índice de reincidência na cidade, a partir de cerca de 4.000 casos, é de $4 \%$, contra um registro de $30 \%$, em média, na capital, em que são aplicados apenas os procedimentos convencionais (internação).

A partir da implantação do NAI em São Carlos, houve redução de 90\% no número de internos enviados à Fundação Casa (antiga Fundaçâao Estadual do Bem-Estar do Menor - 
Febem), e cerca de $96 \%$ dos jovens que cometeram algum ato infracional agora são atendidos no próprio município ${ }^{\text {II }}$.

Ele se constitui como um programa que visa atuar em "rede", congregando vários serviços públicos prestados por diversos órgáos municipais e estaduais no atendimento rápido e eficaz ao adolescente.

Para ilustrar a visibilidade adquirida pela cidade, em reportagem na revista Época Negócios (03 de julho de 2007), selecionei o seguinte trecho:

Por excepcional em seus resultados, o projeto de São Carlos foi premiado na última edição do Programa Gestão Pública e Cidadania, organizado pela Fundação Getúlio Vargas em conjunto com a Fundação Ford. Esse prêmio tem o objetivo de destacar práticas inovadoras na área pública. "Eles conseguiram integrar forças que normalmente não se comunicam, fizeram um projeto super arrojado e hoje recebem gente do Brasil inteiro interessada em descobrir a fórmula", diz o pesquisador Rafael Martins, autor de um estudo sobre São Carlos para o Programa Gestão Pública e Cidadania.

A pauta da Justiça Restaurativa nessa localidade foi incentivada por um procurador geral da prefeitura, na época, mas acabou se esvaindo e culminou com sua não implantação. Hoje, a discussão incide sobre a instalação de uma unidade da Fundação Casa na cidade, como quer o governo estadual, em contraposiçáo ao governo municipal, que a rejeita, reforçando, em vão, a imagem pública positiva do NAI. Essa nova discussáo inviabiliza ainda mais qualquer possibilidade de ressurgimento da pauta da Justiça Restaurativa no município.

Foi observada, nessa localidade, a existência de duas redes sociais principais se cruzando: aquela ligada à internacionalizaçáo do saber sobre acesso à Justiça - representada pela Justiça Restaurativa e seu maior incentivador local - e outra que se liga mais ao campo político, por intermédio do NAI, e que envolve a prefeitura e os profissionais oriundos de diversas áreas da cidade que trabalham no programa de acompanhamento de menores em conflito com a lei.

A questáo que se torna pertinente nesse caso específico pode ser expressa da seguinte forma: por que os profissionais envolvidos com o trabalho do NAI não o entendem como um problema de ingerência política em sua autonomia profissional e se contrapóem à pauta internacional da Justiça Restaurativa? Mais ainda, que motivos levaram São Caetano do Sul a desenvolver outra configuração?

O agente que trouxe a pauta da Justiça Restaurativa para São Carlos partilha de um ethos profissional heterodoxo, em consonância com a vertente do Direito que abarca esse tipo de Justiça alternativa. Efetivamente, infere-se, a partir dos dados colhidos nos estudos de caso, que, além de estar em harmonia com o segmento profissional de visão mais pluralista, o incentivador da pauta na localidade tem ligaçôes com a rede de São Paulo. Sua motivação pela Justiça Restaura-

II Esses dados estão disponíveis no site: <http://www.saocarlos.sp.gov.br/index.php/utilidade-publica/nucleo-deatendimento-integrado-nai.html>, acessado em 24/oi/20Io. 
tiva, que espelha seus laços político-profissionais, resultou em seu deslocamento de São Carlos para ocupar uma posição no Ministério Público, em Brasília, deixando a questáo da Justiça Restaurativa desarticulada no local.

Acredita-se que, diferentemente do que ocorreu em São Carlos, onde a pauta internacional impulsionou seu maior incentivador, deixando a questáo da Justiça Restaurativa sem patrono local, o cruzamento das redes sociais em Sáo Caetano do Sul impulsionou o saber especializado, bem como importadores do modelo. Além disso, Em Sáo Carlos, sobressai a ligação da rede profissional com o campo político, em contraposição ao fortalecimento da institucionalizaçáo da profissão, que é maior em Sáo Caetano do Sul.

Dessa forma, foi possível verificar como a pauta da Justiça Restaurativa se insere de formas diferentes nas duas regiōes e como em São Carlos a menor institucionalização da carreira viabilizou de forma mais fácil o deslocamento do maior incentivador do local para uma nova posiçáo profissional em Brasília.

Portanto, uma parte fundamental do trabalho constitui-se em identificar quem são os importadores dessa agenda global, que, segundo Dezalay e Garth (2002), empoderam-se no processo da mesma forma que aqueles que estáo no centro dos processos de importaçáa e exportaçáo empoderam-se do saber especializado.

Como se deu, entáo, a implantação do paradigma a partir do diálogo com os importadores do saber? Que redes permitiram o fortalecimento da visão heterodoxa em um lugar e seu enfraquecimento em outro?

Giddens (I99I) diz que a globalização desloca as experiências e as noçóes de tempo/espaço, mas estar distante do centro da rede de trocas de saber especializado permite o uso da distância como forma de resistência local, já que aqueles mais perto do centro das redes se envolvem mais com seus conteúdos e sáo mais cobrados. Além disso, essa resistência pode não se caracterizar por uma contestação explícita. James Scott (1990) usa para isso o termo transcrito oculto, ou seja, uma recusa em que não existem enfrentamentos, oposiçôes, lutas abertas. Há o não fazer, as dificuldades, a falta de interessados, etc. É uma maneira difusa de escapar sem enfrentar.

Se aqueles que estáo mais distantes dos centros de troca de expertise sáo menos cobrados e podem utilizar a distância como forma de transcrito oculto, o mesmo não acontece com os importadores da pauta, que podem assumir papel de destaque, estejam nos centros exportadores ou nos locais importadores, como o caso do procurador geral de São Carlos, que se deslocou na profissão.

Em São Carlos foi verificada uma resistência velada, que se traduzia na realidade da falta de tempo, falta de pernas e de pessoas comprometidas. Seguem os depoimentos do ex-secretário da Secretaria Municipal Especial da Infância e Juventude de São Carlos e do juiz, respectivamente, sobre as possibilidades de implantação de um programa de Justiça Restaurativa na cidade:

Eu acho que a questão principal, nesse momento, seria a disponibilidade do Ministério Público e, principalmente, por parte do Judiciário, do juiz da Infância e da Juven- 
tude, por parte do qual eu acredito que não haja nenhuma restrição quanto ao tipo de Justiça. (...) Mas acredito que a dificuldade maior é realmente a questão do tempo, por quê? Por que o NAI acaba demandando do Judiciário um tempo maior para o juiz estar mais disponível para a infância e para a juventude, mas, assim, principalmente esta Vara em Sáo Carlos, ela não é exclusiva. Então, ela é cumulativa com a Vara Criminal. (...) entáo, fica muito difícil para um juiz com essa sobrecarga conseguir dar conta de entrar, desencadear talvez esse outro processo que é o da Justiça Restaurativa (ex-secretário municipal da Secretaria Municipal Especial da Infância e Juventude de São Carlos).

(...) Não acredito que haveria entraves ou objeçôes, o que haverá, isso com certeza, é como eu vou dizer, é a ausência de participação de algumas pessoas, de algumas instituiçôes, por conta de imaginarem que ela talvez não fosse necessária ou não acreditar nela, não de ser contra ela, não é isso (...) (juiz da Vara da Infância e Juventude de São Carlos).

Dadas as diversas variáveis que compóem o problema, podemos aqui estender o argumento sobre o qual o estudo se pauta e discutir uma possível diluição do impacto à importação e à exportação de saber especializado, do global para o local, em São Carlos, que não teria acontecido em São Caetano do Sul. Existe a possibilidade de que a força das redes constituídas em torno do novo paradigma tenha se diluído em uma localidade diferentemente da outra, dado que esse saber especializado a respeito do acesso à Justiça perpassa algumas instâncias e os compromissos do Estado brasileiro com agências internacionais.

Assim, nos discursos recolhidos em São Carlos, todos, a princípio, declaravam-se favoráveis, mas, depois, começavam a apontar ressalvas, mostrando que a posição, na verdade, não era assim tão favorável. Entre aqueles profissionais mais ligados ao NAI, a inquietação parece ser resultante do medo de que a Justiça Restaurativa venha a atrapalhar um plano de atuaçáo sobre o menor que já caminha bem. Já em relação ao entrevistado que tive como representante da Ordem dos Advogados do Brasil, na localidade, a preocupação reside em se firmarem sempre limites sobre os quais a Justiça Restaurativa poderia atuar para que não saia do campo sob jurisdição da OAB. Existe, portanto, uma preocupaçáo por parte da organização em estabelecer os limites de uma possível interlocução com o campo político:

Eu digo assim, esse princípio que nós falávamos da Justiça Restaurativa, nós somos favoráveis, mas tudo com seriedade, com o acompanhamento da própria $\mathrm{OAB}$, que, na verdade, é uma instituição responsável pela garantia dos direitos individuais, coletivos, isso é histórico, também, que eles sejam cumpridos (vice-presidente da OAB de São Carlos).

Outra forma de resistência localizada no contexto de São Carlos refere-se à negociação de significados, um conceito-chave da vertente sociológica do interacionismo simbólico, que a vê como uma forma de agência, e não sujeição dos indivíduos. Foram encontradas, entre os entre- 
vistados, diversas opinióes a respeito do que seria a Justiça Restaurativa; alguns se aproximaram mais dos usos correntes; outros se afastaram mais; um entrevistado desconhecia o modelo.

É interessante notar que, para o promotor da área na cidade, a Justiça Restaurativa se aproxima muito daquele trabalho que ele já desenvolvia na cidade e aponta que somente dessa forma seria bem-vinda:

Se você entender como Justiça Restaurativa aquela Justiça que vem a restaurar uma situação natural, onde aquilo devia estar acontecendo, quer dizer, o seio familiar é o principal, então, acho que, de repente, a Justiça Restaurativa a gente pode estar mudando de nome e falando de apoio familiar. (...) Eu acho que seria bem-vindo, eu acho que aí, mas, assim, focando a questão familiar, tá? (promotor da Vara da Infância e Juventude de Sáo Carlos).

Essa é uma forma de oposiçãa, pois, quanto mais conformamos o modelo segundo o que acreditamos ser, menos abertura damos a ele, como ele mesmo se apresenta. Esse manuseio de significados é uma forma de resistência velada, por permitir o aumento da diluiçáo da proposta na localidade; nesse sentido, quanto mais nos "distanciamos", mais a negociaçáo de significados a respeito da Justiça Restaurativa se afasta do perfil original.

Dessa maneira, a "recusa" em São Carlos e a "aceitaçáo" em São Caetano do Sul aos novos valores dão margem para verificar as dificuldades e resistências que um programa ligado à Justiça Restaurativa enfrenta para conseguir ser colocado em prática. Esse modelo de mediaçáo, que é uma das formas que podem fortalecer o ideário heterodoxo que vem tomando espaço entre as tendências existentes na profissáo do Direito, gera apoios e críticas, como o presente estudo, que almeja verificar em um espaço mais delimitado.

\section{SÃO CAETANO DO SUL}

No mesmo ano de 2005, em outra localidade, Sáo Caetano do Sul, foi implantado um programa-piloto de Justiça Restaurativa nas escolas públicas do município, visando mediar, no próprio ambiente escolar, os conflitos internos à escola, problemas entre alunos, professores e funcionários.

O programa de Justiça Restaurativa nessa cidade funciona desde julho de 2005 e conta com o apoio institucional do Tribunal de Justiça do Estado. Ele tem se desenvolvido a partir de uma parceria do Judiciário com as escolas e teve como um de seus elaboradores e coordenadores o juiz da I a Vara da Infância e Juventude de São Caetano do Sul. O juiz é, no Brasil, hoje, um dos principais defensores do modelo e também um grande propagador de seu uso. 
Nessa cidade, o programa começa sendo aplicado nas escolas. Nesse contexto, pretende diminuir a violência, principalmente tratando dos casos de bullying $g^{12}$. O movimento foi de primeiro atender os casos nas escolas e, posteriormente, começar a envolver mais a comunidade e resolver casos fora do âmbito escolar.

Nos países em que os projetos de Justiça Restaurativa estão em fase mais avançada, chegam a ser atendidos casos de maior potencial ofensivo. Aqui no Brasil, entretanto, é dada maior atenção aos casos que envolvem menores e conflitos em ambiente escolar, como é o caso de São Caetano do Sul.

Fazendo um retrospecto do desenvolvimento do programa nessa cidade, a partir da literatura elaborada por seus próprios organizadores ${ }^{13}$, temos que, em uma primeira etapa, o foco do projeto eram as escolas e os adolescentes em conflito com a lei, sob o título: "Justiça e Educação: parceria para a cidadania”. As mediaçóes ocorriam, além de nas escolas, no Fórum e no Conselho Tutelar. Assim, em meados de 2005, o juiz mobilizou parceiros no Judiciário para a concretização do projeto, que envolvia, nessa época, apenas três escolas. Foram eles: a Secretaria de Estado da Educação, que, por sua vez, autorizou a Diretoria de Ensino de São Bernardo do Campo - essa diretoria é responsável também pelas escolas de São Caetano do Sul -, o Conselho Municipal de Direitos da Criança e do Adolescente, o Conselho Tutelar, o Conselho Municipal de Segurança, o Cartório da Infância e da Juventude, entre outras instituiçóes. Outros importantes parceiros nesse processo são o constantemente citado Centro de Criaçăo de Imagem Popular (Cecip) e a APS Internacional da Holanda, ambas ONGs.

Nesse primeiro momento do programa na cidade, eram três os principais objetivos: primeiramente, evitar o encaminhamento de casos escolares para os trâmites judiciais criminais; em segundo lugar, atuar no âmbito do Fórum, realizando círculos nesse espaço; e, em terceiro e último lugar, fortalecer a rede de atendimento que atua sobre o adolescente em conflito com a lei.

O segundo movimento do projeto em São Caetano do Sul foi a ampliaçáo do escopo da resolução dos conflitos sob o paradigma restaurativo para a comunidade em geral. Instaurouse, então, o $2^{\circ}$ Piloto na Comarca: "Restaurando Justiça na Família e na Vizinhança: Justiça Restaurativa e Comunitária no bairro Nova Gerty”. Nova Gerty é considerado um dos bairros com maior concentraçáo de episódios de violência na cidade. Ali, os círculos são realizados no espaço da Escola Estadual Padre Alexandre Grigoli e visavam, inicialmente, atender conflitos domésticos e de vizinhança, em uma parceria com a Guarda Municipal, a Polícia Militar e o Programa de Saúde da Família. A iniciativa de Justiça comunitária contou também com o apoio da prefeitura do município.

I2 $\mathrm{O}$ bullying é um termo de origem inglesa - ainda não há tradução para o português - utilizado para descrever violências físicas ou morais que geralmente ocorrem em ambientes escolares. Pode ser definido, em linhas gerais, como uma atitude agressiva e intencional dirigida repetitivamente a um indivíduo ou grupo, a partir de uma relaçáo desigual de poder. Para mais informaçôes, acesse: <http://www.bullying.org/>.

I3 Os dados para essa explanação foram recolhidos do livro Justiça Restaurativa e Comunitária em São Caetano do Sul-aprendendo com os conflitos a respeitar direitos e promover cidadania (2008a), de Eduardo Rezende Melo, Madza Ednir e Vânia Curi Yazbek. 
Além disso, em 2006 mais escolas aderiram ao projeto; nesse caso, todas as i2 escolas da rede estadual de São Caetano do Sul.

Em setembro do mesmo ano, a Secretaria de Estado da Educação de Sáo Paulo, com o apoio do MEC, decidiu apoiar a ampliação do projeto para mais duas Diretorias de Ensino: em Heliópolis (São Paulo) e Guarulhos. Como consta no material sobre o programa em São Caetano do Sul, na cidade de Campinas, um projeto de mesma natureza iniciou-se em 2008. Essas extensôes contaram com o apoio financeiro do Ministério da Educação, que repassou verbas do Fundo Nacional de Desenvolvimento de Educaçáo (FNDE) à Secretaria de Estado da Educação de São Paulo, via Fundação para o Desenvolvimento da Educação (FDE).

A partir, entấo, do chamado terceiro movimento do projeto em São Caetano do Sul, a preocupação volta-se com o aperfeiçoamento do programa e melhor articulação ou adequação entre seus principais órgáos ou atores, ou mesmo melhoras nos atendimentos prestados e nas capacitaçóes para aqueles engajados no projeto.

Desde o início até dezembro de 2007, foram realizados 260 círculos restaurativos, e o projeto tornou-se parte da política de atendimento aos adolescentes em conflito, de acordo com a lei, com a resoluçáa do Conselho Municipal de Direitos da Criança e do Adolescente. Segundo Melo (2008b), em três anos de projeto, mais de mil pessoas foram atendidas, com índice de acordo de $88 \%$; e destes, $96 \%$ foram cumpridos.

Fazem parte do programa de Justiça Restaurativa em São Caetano do Sul profissionais de diversas áreas: policiais, psicólogos, pedagogos, advogados, promotores, delegados, entre outros. Segundo os organizadores do projeto, se os profissionais não atuam diretamente na realização de mediaçóes e capacitaçóes de mediadores ou em sua divulgaçáo, eles podem participar como "encaminhadores". Dessa forma, é sempre destacada a importância de se conscientizar o maior número de profissionais sobre os procedimentos da Justiça Restaurativa, pois isso permitiria que o primeiro contato das pessoas com a Justiça Restaurativa fosse de qualidade e que os profissionais pudessem, portanto, verificar que casos dáo margem para a realizaçáo de um círculo. Esse discurso indica um movimento de autorrealização do profissional envolvido com a questão na localidade.

A partir da mesma fonte bibliográfica, produzida pelos próprios organizadores do modelo em São Caetano do Sul, que ilustra a visão oficial sobre o projeto, agora os principais objetivos referem-se à maior institucionalizaçáo do programa, com a proposta de reconhecimento formal das atividades dos facilitadores de Justiça em ambiente escolar, elaboração de um plano de carreira para facilitadores dentro do projeto restaurativo, no âmbito da Secretaria de Justiça e da Educaçáo.

Isso mostra, mais uma vez, que a profissionalização tem papel de destaque na localidade. Além disso, um dado importante ressaltado pelos organizadores do livro alude ao fato de que o projeto ganha consistência na medida em que dois dos coordenadores de projetos de Justiça Restaurativa no país, em São Caetano do Sul e Porto Alegre, são membros da Associaçáo Brasileira de Magistrados e Promotores de Justiça (ABMP) e Defensoria Pública da Infância e Juventude; o primeiro, seu atual presidente; o segundo, seu ex-presidente. 
É importante ressaltar também que se ampliou o "espaço" da Justiça Restaurativa quando a própria Escola Paulista de Magistratura criou um curso sobre o tema. É um curso de 60 horas/ aula, ministradas por um conjunto diversificado de atores. Participam do curso operadores do Direito (promotores de Justiça e advogados) e outros atores (guardas, policiais, conselheiros tutelares, agentes de grupos de suporte e de atendimento, diretores de escolas). O juiz responsável pela implementaçáo do projeto de São Caetano do Sul também é o coordenador do curso de Justiça Restaurativa da Escola Paulista da Magistratura.

Se, nessa localidade, a institucionalização das carreiras facilitou a inserção da pauta, por outro lado, ela problematiza sua continuidade. Foi possível depreender dos relatos como a Justiça Restaurativa enfrenta dificuldades de se instalar em alguns lugares, por não se conseguir a adesão dos principais operadores do Direito do lugar. Da mesma maneira, argumenta-se sobre como a pauta acaba se tornando dependente da atuaçáo de alguns agentes específicos, como fica claro no depoimento do ex-assessor da Secretaria da Reforma do Judiciário, que colaborou na viabilização dos projetos-piloto:

Existem, em alguns tribunais, portarias, algum grau de normatizaçáo dos programas que conferem alguma segurança, mas esse grau de institucionalização, no meu entender, é bastante frágil ainda, eu vejo uma coisa muito personalizada, você não fala do projeto da $2^{\mathrm{a}}$ Vara de Execução de Medidas Socioeducativas de Porto Alegre, o projeto é do Dr. ... (nome), eu não falo do projeto da Vara da Infância e Juventude de São Caetano, o nome do projeto: ... (nome), eu náo falo do Juizado Especial Cível, eu falo do projeto do ... (nome) e do promotor, cujo nome me escapa agora. Então, o receio, evidentemente, é de que, com a remoção, enfim, com a saída desses juízes desses locais, o projeto náo tenha prosseguimento.

Se a Justiça Restaurativa se mostra intrinsecamente ligada aos seus principais idealizadores, também é ressaltado no estudo de caso o papel fundamental que vêm exercendo os facilitadores de Justiça em São Caetano do Sul. A presença em círculos restaurativos e entrevistas com facilitadores atuantes no projeto da cidade foi fundamental para o prosseguimento do estudo, porque todo o esforço empreendido para a continuaçáo do programa náo aparece nas bibliografias oficiais, $\mathrm{o}$ que dá uma nova dimensão para a análise.

De acordo com o relato de alguns facilitadores, obtidos por meio de entrevistas, à época da instalaçấo do projeto, cerca de trinta pessoas participaram da primeira capacitação para formação de mediadores, ocorrida em julho de 2006. Ainda em março de 2008, mais doze ou quinze pessoas foram capacitadas. Atualmente, o projeto conta com apenas seis facilitadores; destes seis, apenas três são facilitadores fixos, isto é, vão todas as quartas e sábados aos plantóes que acontecem na Escola Estadual Padre Alexandre Grigoli, os demais vão esporadicamente para ajudar. As próprias facilitadoras, as três que restaram, assumem: "Agora, aqui em São Caetano, se a gente parasse, uma de nós parasse, o projeto acaba!". 
Interessante notar que, nos dois círculos a que a pesquisadora teve a oportunidade de assistir, foi muito ressaltado o fraco papel da instituiçáo escola como mediadora na resoluçáo de conflitos que anteriormente ficavam circunscritos ao ambiente escolar. Hoje, esses conflitos ultrapassam os muros das escolas e vão para a delegacia, culminando em muitos processos judiciais. Se não for a principal ideia norteadora do projeto, pelo menos é uma das mais importantes: tentar "resolver os conflitos escolares no próprio ambiente da escola”, mas o que se verifica é um processo inverso, em que os conflitos escolares (professor versus aluno ou aluno versus aluno) saem dos limites da escola e vão para delegacias e fóruns, e o juiz é quem tem indicado os casos a serem resolvidos pelo projeto de Justiça Restaurativa, voltando, entáo, para o lugar de onde deveria ter partido.

Segundo um dos facilitadores de Justiça: "Hoje é muito fácil fazer BO (Boletim de Ocorrência), é por isso que fez o projeto-piloto, porque tem muito BO nesse bairro". O foco do projeto parece incidir, portanto, no espaço vazio que a escola tem criado com sua "imparcialidade" perante a crescente marginalização do espaço.

\section{INTERNACIONALIZAÇÃO DO SABER JURÍDICO E REDES PROFISSIONAIS LOCAIS - ALGUMAS QUESTÕES PONTUAIS}

Em São Caetano do Sul, a pauta desloca também incentivadores, como aconteceu em São Carlos, mas a diferença consiste em que a força instituída das redes nesse contexto é mais forte, e as coaçóes não podem ser mediadas aqui pela distância do centro que se liga à rede internacional, em relação à localidade. É interessante notar também que praticamente todos aqueles que se deslocaram na carreira, envolvidos com a questâo da Justiça Restaurativa, desligaram-se da pauta ou, pelo menos, reduziram muito sua atuação junto ao fortalecimento do paradigma. Dessa forma, os profissionais observados pela pesquisa que apoiaram a Justiça Restaurativa e que se aproximaram mais da política, ocupando cargos no Executivo, não se desvincularam da carreira voltando a exercer a ocupaçáo de antes. Esse fato demonstra como, na verdade, não tem sido a Justiça Restaurativa quem tem alcançado novas dimensóes, e, sim, os participantes da rede que se ligam à pauta.

Sobre o engajamento dos magistrados nesse processo de importação de saber, pode-se dizer que ele náo representa um fato isolado; como fenômeno social, ele faz parte de um quadro mais complexo, composto de outras variáveis. Um ponto de vista manifestado nas entrevistas liga o novo papel do magistrado à formulação das leis pelo Poder Legislativo. Segundo esse raciocínio, o legislador, hoje, passa por um movimento consciente de deixar em aberto muitos conteúdos das leis - especialmente as do Direito Criminal -, de forma que esse espaço vazio criado entre as definiçóes passe a ser preenchido pelo juiz. Isso aumentaria ainda mais as novas demandas políticas entre as prerrogativas profissionais dos juízes.

Vianna, Carvalho, Melo e Burgos (1997) já discutiam esse processo de "desneutralização" da figura do juiz. Na medida em que foram introduzidos princípios de Justiça na aplicaçáo das normas, espera-se da atuação do juiz que ele leve em consideração os efeitos sociais desejáveis ou expectativas de promoçáa de direitos que se encontram imbuídos nos textos constitucionais. 
A esse processo chamamos "judicialização da política", como já indicado anteriormente, e dele resulta o fato de que agora o Judiciário tem de lidar com questốes de ordem legislativa e executiva, com participação na implementação de políticas públicas (SinHORETTO, 2006).

Observa-se, na fala do juiz responsável pela ampliaçáo do projeto para o bairro de Heliópolis, como o tamanho da localidade influencia muito na prosperidade de um projeto dessa magnitude. Nesse caso, em Sáo Caetano do Sul, por exemplo, o juiz nesse local concentra muitas competências em torno dele, o que facilitaria o desenvolvimento do programa. Já em São Paulo, o conteúdo fragmentar-se-ia, na medida em que ele perpassa vários outros personagens, são outros juízes, outras áreas que acabam entrando em contato, e isso dificultaria. Segundo sua opiniáo, portanto, a autonomia em uma comarca menor é muito maior, o que o impele a dizer que as possibilidades de sucesso de um programa desse cunho seriam maiores, se implementado em comarcas com menores dimensóes. Entretanto, os dados revelam como a pauta justamente realizou o caminho inverso, partindo de grandes centros urbanos para agora começar a chegar até regiōes de menores dimensôes, cidades do interior.

Foi observado, nas falas dos entrevistados dos grandes centros, um receio sobre a liderança de um projeto desse tipo: por se tratar justamente de um grande centro, é maior também a responsabilidade, e uma falha no desenvolvimento do programa poderia abalar suas prerrogativas profissionais.

Nenhum dos entrevistados se dedica somente à Justiça Restaurativa, eles efetivamente têm que lidar com duas vertentes diferentes. Existe uma divergência entre os ideários que se revela na dificuldade de instauração do conteúdo e nas pequenas interaçóes do dia a dia, nas "piadinhas" entre colegas.

Nas lideranças educacionais, na pessoa que está na escola, é responsável pela implementação do projeto, tem que capacitar elas para lidar com esse tipo de situação, e entender é tudo, né, uma piada que se faz de você. Já falaram que eu sou "restaurador de dente", quer dizer, ou vai abraçar árvore, daqui a pouco, você está abraçando árvore. Tudo isso você tem. Então, como você lida com isso? Numa boa, mas para lidar numa boa, e tem que ser, quer dizer, ótimo que seja numa boa, mas já é um teste para você aí no seu projeto de vida (juiz de Sáo Paulo).

Fica evidente, nesse caso, como a Justiça Restaurativa, mais do que se opor à neutralidade ressaltada pelo profissionalismo, ela vem se delineando, de acordo com os pares, como contraponto à expertise e à reserva de mercado. $\mathrm{O}$ que se questiona, na verdade, no contexto, é se a pauta é ou não expertise.

\section{CONCLUSÕES}

Sobre resistências ao modelo de resoluçáo de conflitos discutido aqui, são diversas as opiniôes. Em geral, todos apontam a existência de oposiçóes, mas a maioria reluta em prosseguir no assunto 
e aponta como causa principal dessa resistência certo desconhecimento dos opositores em relaçáo ao tema. Segundo muitos entrevistados, se soubessem mais a respeito da Justiça Restaurativa, seus princípios e objetivos, mudariam de opiniáo.

Alguns entrevistados começam com esse tipo de discurso, quando indagados a respeito dessas críticas, e depois vão aprofundando os relatos, de maneira que terminam por falar mais abertamente a respeito das restriçóes e de onde elas vêm. Poucos ainda são aqueles que falam de forma clara e sem receios a respeito do assunto. Concluindo, aqueles envolvidos com o conteúdo do modelo alternativo, em geral, relatam que as resistências advêm "de fora" e devido à ignorância sobre o tema. Quando a crítica acontece, nunca ou muito dificilmente isso ocorre de forma explícita; em geral, é na forma de não adesáo. Finalmente, foi possível inferir dos depoimentos que as principais críticas vêm de alguns grupos profissionais específicos, como promotores, policiais, Ministério Público. As razóes seguem pensamentos diversos, que indicam desde a reserva de mercado até o medo de perda relativa de poder, entre outros.

Ao contrário de Sáo Carlos, na regiáo de Sáo Caetano do Sul, os profissionais envolvidos com o programa de Justiça Restaurativa não entendem esse conteúdo como um problema de intervenção de ordem política sobre sua autonomia profissional - que é fundamentada também em um ideário de neutralidade. Contudo, eles têm que "conviver" com profissionais que, de forma diferente, entendem a pauta como um problema na carreira. Isso, de uma forma ou de outra, acaba refletindo sobre esses profissionais, especialmente aqueles do Direito envolvidos na aplicação do modelo informal, ainda que internalizem isso de formas diferenciadas.

Tal fato pode ser verificado a partir dos discursos que manifestam o "receio" de encabeçar programas desse cunho em grandes centros, onde a estrutura é mais complexa ou na ideia de que é preciso ter uma "mente mais aberta" para não se abalar com eventuais comentários e piadas de colegas, o que levaria a uma necessidade de acompanhamento dos envolvidos no programa para não se desmotivarem. Também é ilustrada na própria opiniáo de que o conteúdo "muda a postura dos profissionais" de forma positiva e de que, antes de participar, isso requereria já um olhar profissional diferente, mais humano.

Finalmente, foi possível inferir três principais diferenças em relação às duas localidades estudadas: elas referem-se à força das redes constituídas em torno do ideário alternativo, as distâncias, traduzidas em formas de inserção ou não, dos grupos profissionais locais, em relação aos centros de troca de expertise, que permite que, em São Carlos, isso seja utilizado como forma de resistência velada, e, por fim, a institucionalização da carreira, que é mais forte em São Caetano do Sul.

A Justiça Restaurativa chega até os dois locais estudados de maneiras diferentes: em um local mais ligada à política e, no outro, por intermédio das carreiras institucionalizadas do Direito. Nesse último caso, a institucionalização da carreira dos receptores da pauta global passa também a se impor como barreira. As duas localidades, portanto, encontram resistências, mas elas vêm de lugares diferentes e se relacionam diretamente à principal característica encontrada nas redes profissionais: uma rede é mais política, enquanto a outra é mais profissional. 


\section{FONTES CONSULTADAS}

Bonelli, Maria da Gloria. A autonomia profissional como a singularidade do profissionalismo. Revista Teoria e Pesquisa, UFSCar, n. 40 e 4I, jan./jul. 2002a.

. Profissionalismo e política no mundo do Direito: as relaçóes dos advogados, desembargadores, procuradores de justiça e delegados de polícia com o Estado. São Carlos, SP: EdUFSCar; Editora Sumaré, $2002 b$.

Bonelli, Maria da Gloria; Oliveira, Fabiana L. de; Martins, Rennê. Profissóes jurídicas, identidades e imagem pública. São Carlos, SP: EdUFSCar, 2006.

Bonelli, Maria da Gloria; Oliveira, Fabiana L. de; Martins, Rennê. A recepção local da homogeneização do complexo jurídico global: estudo de caso dos juízes de São Paulo. In: Congresso Sócio Jurídico de Oñati, II, 2007.

Cavalcanti, Rosângela B. Cidadania e acesso à Justiça: Promotorias de Justiça da comunidade. São Paulo: Idesp; Editora Sumaré, I999.

De Vitto, Renato C. P. “Justiça Criminal, Justiça Restaurativa e direitos humanos”. In: Slakmon, C.; De Vitto, R.; Gomes Pinto, R. (Orgs.) Justiça Restaurativa. Brasília: Ministério da Justiça e PNUD, 2005.

Dezalay, Yves; Garth, Bryant. A dolarização do conhecimento técnico-profissional e do Estado: processos transnacionais e questôes de legitimação na transformação do Estado. 1960-2000. Revista Brasileira de Ciências Sociais, n. 43, junho 2000.

The internationalization of palace of wars: lawyers, economists, and the contest to transform Latin American State. Chicago: The Chicago Series Law \& Society, April 2002.

Dubar, Claude. A socializaçâo: construção das identidades sociais e profissionais. São Paulo: Martins Fontes, 2005.

Engelmann, Fabiano. Sociologia do campo jurídico: juristas e usos do Direito. Porto Alegre: Sergio Antonio Fabris Editora, 2006a.

. Internacionalização e ativismo judicial: as causas coletivas. Revista Lua Nova, n. 69, pp. I23-I46, 2006b.

Foucault, Michel. Os anormais. São Paulo: Martins Fontes, $200 \mathrm{I}$.

Foucault, Michel. Vigiar e punir. Petrópolis: Vozes, 2004.

Freidson, Eliot. Para uma análise comparada das profissóes: a institucionalização do discurso e do conhecimento formais. Revista Brasileira de Ciências Sociais, n. 3I, junho de 1996. 
_. Renascimento do profissionalismo. São Paulo: Edusp, 1998.

. Professionalism, the third logic: on the practice of knowledge. Chicago: The University of Chicago Press, 200I.

Giddens, Anthony. As consequências da modernidade. 2. ed. Sáo Paulo: Unesp, I99i.

Goffman, Erving. A representação do eu na vida cotidiana. I3. ed. Rio de Janeiro, Petrópolis: Editora Vozes, 2003.

Gomes Pinto, R.; Slakmon, C.; De Vitto, R. (Orgs.) Justiça restaurativa. Brasília: Ministério da Justiça e PNUD, 2005.

Halliday, T. Beyond monopoly: lawyers, state crises, and professional empowerment. Chicago: University of Chicago Press, 1987.

Marques Jr., Gessé. Fundamentos sociológicos do sentimento de frustração profissional entre magistrados e promotores. In: Congresso Brasileiro de Sociologia, 24. Anais... 2009.

Melo, Eduardo R. "Justiça Restaurativa e seus desafios histórico-culturais: um ensaio crítico sobre os fundamentos ético-filosóficos da Justiça Restaurativa em contraposição à Justiça Retributiva”. In: Slakmon, C.; De Vitto, R.; Gomes Pinto, R. (Orgs.) Justiça Restaurativa. Brasília: Ministério da Justiça e PNUD, 2005 .

. "Comunidade e justiça em parceria para a promoção de respeito e civilidade nas relaçóes familiares e de vizinhança: um experimento de Justiça Restaurativa e comunitária. Bairro Nova Gerty, São Caetano do Sul/SP”. In: Slakmon, Catherine; Machado, Maíra Rocha; Bottini, Pierpaolo Cruz (Orgs.) Novas direçóes na governança da Justiça e da segurança. Brasília, DF: Ministério da Justiça, 2006.

Melo, Eduardo R.; Ednir, Madza; Yazbek, Vania C. Justiça Restaurativa e Comunitária em São Caetano do Sul: aprendendo com os conflitos a respeitar direitos e promover cidadania. Secretaria Especial dos Direitos Humanos da Presidência da República. Rio de Janeiro: Cecip, 2008a.

A experiência em Justiça Restaurativa no Brasil: um novo paradigma avançado na infância e juventude. Revista IOB de Direito Penal e Processual Penal, Porto Alegre, ano IX, n. 5I, pp.I5O-I54, ago./set. 2008b.

Miraglia, Paula. Aprendendo a lição: uma etnografia das Varas Especiais da Infância e Juventude. Novos Estudos Cebrap, n. 72, pp. 79-98, julho 2005.

Olson, S. M.; Dzur, A. W. Revisiting informal justice: restorative justice and democratic professionalism. Law \& Society Review, v. 38, n. I, 2004. 
SADek, Maria T. (Org.) O Judiciário em debate. (Série Justiça) São Paulo: Idesp; Editora Sumaré, 1995.

Judiciário: mudanças e reformas. Revista Estudos Avançados, São Paulo, v. I8, n. 5I, maio/ago. 2004 .

Sadek, Maria T.; Arantes, R. B.; Sanches Filho, A. O. (Orgs.) Reforma do Judiciário. São Paulo: Fundação Konrad Adenauer, 2002.

Sales, Lília Maia de M. Mediação de conflitos: família, escola e comunidade. Florianópolis: Conceito Editorial, 2007a.

. Access to Justice: small claims courts in Brazil. In: Encontro Anual the Law and Society Association, TBA. Berlin, Germany, Jul 25, 2007b.

Santos, Boaventura de S. Para uma revolução democrática de justiça. São Paulo: Editora Cortez, 2007.

Schuch, Patrice. Direitos e afetos: análise etnográfica da "Justiça Restaurativa" no Brasil. In: Anpocs. 24 a 28 de outubro, 2006.

Scотт, James C. Domination and the arts of resistance. Yale: Yale University Press, I990.

Sinhoretto, J. Ir aonde o povo está: etnografia de uma reforma da justiça. 2006. Tese (Doutorado) - Universidade de Sáo Paulo.

Vianna, Luiz Werneck; Carvalho, Maria A. R. de; Melo, Manuel P. C.; Burgos, Marcelo B. Corpo e alma da magistratura brasileira. 2. ed. Rio de Janeiro: Revan, 1997.

VIANnA, Luiz Werneck et al. A judicialização da política e das relaçôes sociais no Brasil. Rio de Janeiro: Editora Revan, I999. 